this up. A serious difficulty to be overcome is the prevalence of piracy. Although registration and licence fees in Bombay amount to only ten rupees a year, it is believed that about fifty per cent of the listeners-in are 'pirates'. As many modern sets work without an aerial, it is particularly difficult to bring the pirates to book. An officer has power to inspect and search houses and a severe penalty is exacted, but the evil still exists.

\section{An Alternative to the Severn Barrage}

IN supplying electrical energy economically, it is very desirable that all the machines in use should be running as nearly as possible continuously at their full load. The overhead costs divided by the output will thus be a minimum. If the machinery were only to run for one hour per day at full load and for 23 hours per day at a tenth load, nine-tenths of the machines would be lying idle most of the time. If a cheap method of storing electrical energy could be invented, we could effect great economies by having only a few machines, all of which would run fully loaded. In an article in the Times of August 24, Mr. J. W. Meares criticises the Severn barrage scheme from this point of view. Between the ebb and flow of the tide there are periods when the turbines must necessarily be inactive, and hence the load on them would be far from being continuous. The chief item in the cost of the scheme is the dam itself. Provision would probably be made for utilising the fortnightly spring tides, and so the load would have a fortnightly fluctuation superposed on the usual twice-a-day one. Mr. Meares suggests that, without using the tides at all, a great deal of electric energy might be generated and stored at some of our steam driven stations. All that would be necessary is to use them to pump water to some elevated reservoir, one situated on a hill for example. At times of peak load this water could be used to drive turbo-electric sets, the electricity generated being transmitted to help supply the load. At first sight it appears a much cheaper method of helping the national supply than utilising the tides. In many cases also the necessary works could be completed in a fraction of the time required for the Severn barrage. It is satisfactory to remember that when the price of coal gets much dearer, we have always tidal power in reserve.

\section{Electric Lighting in the Isle of Man}

IN 1928 a commission was appointed to inquire into the best methods of supplying the Isle of Man with electric light and power. This resulted in the appointment of an Electricity Board in 1932 to carry out a scheme of supply which is not unlike that adopted in the English 'grid'. The scheme covers the whole of the island except 17 square miles supplied by the Douglas Corporation. It consists broadly of an overhead ring main at 33 kilovolts from which tappings can be taken for the consumers. According to the Electrical Times for August 10, the first part of the line was inaugurated on August 3. Considering that the first pole of the line was erected on April 18, this shows how expert electricians have become in overhead construction. There are now approximately seventy miles of steelcored aluminium conductors erected. The supply is taken from the Douglas Corporation works, the supply being stepped up from 3,300 to 33,000 volts at a sub. station before it comes to the high tension ring main. The overhead lines are carried on creosoted fir poles, but $H$ poles are used in special positions. Although the lines operate at $\mathbf{3 3}$ kilovolts, they satisfy the British Standard Specification for 66 kilovolts. The low-tension substations connected with the ring main supply consumers at 400 volts for power and 230 volts for lighting. The normal span adopted between poles is $\mathbf{4 0 0}$ feet but in a few cases it was necessary to resort to much longer spans on account of the contour of the ground and way leave difficulties. The longest span of $1,013 \mathrm{ft}$. is at the well-known Laxey Glen. The supports on each side of this span are threo poles, each pole carrying one of the three phase conductors.

\section{Synthetic Corundum for Jewel Bearings}

IN 1904 Prof. A. Verneuil published an account of his successful experiments on the artificial reproduction of ruby. He pointed out at the time that his method of crystallising was of considerable commercial interest, but at first most attention was paid to producing decorative gems. The watchmaking industry was the first to adopt these gems for the bearings in watches. Their uniform colour and moderate price have led to their general adoption in this industry. In a paper on "Synthetic Corundum for Jewel Bearings" by E. G. Landmeier, published in the Journal of the Institution of Electrical Engineers for May, a description is given of the manufacturing processes used in the production of rough synthetic corundum and of jewel bearings for electric meters and other measuring instruments. A description is also given of the methods now used for the synthesis of sapphire. It was stated that it is difficult to obtain natural stones as hard and as uniform as synthetic ones. A few years ago, practical men found it difficult to believe that synthetic stones grown in the chernical laboratory in a few hours could equal natural stones. It has to be remembered that special processes have now made it possible to obtain for the synthesis of corundum raw material of the highest purity, which is only rarely found in Nature. Numerous photographs are shown illustrating the effect of a rotating pivot on the jewel. Communications from several engineers discussing the author's conclusions are published at the end of the paper. Manufacturers of meters apparently are not yet agreed as to the relative lengths of the lives of the synthetic and natural jewel bearings.

\section{World Oil Production}

The Petroleum Economics Division of the United States Bureau of Mines has recently published results of its annual statistical survey of the world crude petroleum production for 1932 (Mineral Market Reports No. 183). During this year the total amount produced was 1,305 million barrels, representing a 